\title{
DOCENTE OU DOENTE: COMO FICA A ROTINA DOS PROFISSIONAIS DA EDUCAÇÃO COM O CRESCENTE ADOECIMENTO EMOCIONAL? ${ }^{1}$
}

\author{
Rosiane Alves Palacios ${ }^{2}$ \\ Carolina Freddo Fleck ${ }^{3}$
}

\begin{abstract}
Resumo 4
Esta pesquisa buscou identificar as consequências geradas pelo aumento das patologias emocionais na rotina de trabalho dos professores da rede estadual de ensino do Rio Grande do Sul. Para tal, foi realizado um estudo narrativo, a partir de entrevistas e grupo focal, aplicados com professores da rede estadual de ensino, utilizandose como técnica de análise, a análise de conteúdo interpretativa. Os resultados indicam que, além de sobrecarregar os docentes remanescentes, o adoecimento crescente dos docentes compromete a qualidade das aulas, da formação e educação dos alunos.

Palavras-chave: Patologias; Professores; Estado; Adoecimento no Trabalho.

PROFESOR O PACIENTE: ¿CÓMO ES LA RUTINA DE LOS PROFESIONALES DE LA EDUCACIÓN CON LA ENFERMEDAD EMOCIONAL EN INCREMENTO?
\end{abstract}

\section{Resumen}

Esta investigación tuvo como objetivo identificar las consecuencias generadas por el aumento de los trastornos laborales emocionales en el trabajo de los maestros de las escuelas estatales de Rio Grande do Sul. La investigación se realizó en un estudio narrativo, estructurado en entrevistas y grupos focales aplicados con maestros de las escuelas del sistema estatal que pertenecen al estado de Rio Grande do Sul, utilizando como técnica de análisis de datos el análisis de contenido interpretativo. La conclusión muestra que, además de sobrecargar a los maestros restantes, la creciente enfermedad de los profesionales de la educación comprometidos con la calidad de las clases en general.

Palabra chave: Patologías; Profesores; Estado; Enfermedad laboral.

\section{TEACHER OR PATIENT: HOW IS THE ROUTINE OF EDUCATION PROFESSIONALS WITH INCREASING EMOTIONAL ILLNESS?}

\begin{abstract}
This research aimed to identify the consequences generated by increased emotional labor disorders in the routine work of teachers of state schools of Rio Grande do Sul. Research was conducted in a narrative study, structured in interviews and focus group applied with teachers from the state system schools who belongs to the state of Rio Grande do Sul, using as data analysis technique to interpretive content analysis. Conclusion shows that besides overloading the remaining teachers, the increasing illness of education professionals committed to quality of classes in general.
\end{abstract}

Keyword: Pathologies; Teachers; State; Work Dis

\footnotetext{
${ }^{1}$ Artigo recebido em 28/08/2019. Primeira avaliação em 07/03/2019. Segunda avaliação em 07/02/2020. Aprovado em 23/04/2020. Publicado em 22/05/2020.

DOI: https://doi.org/10.22409/tn.v18i36.34746

${ }^{2}$ Administradora, mestranda do Programa de Pós-graduação em Administração da Pontifícia Universidade Católica do Rio Grande do Sul (PUCRS) - Brasil, E-mail: rosiane.palacios@edu.pucrs.br, ORCID: 0000-0002-7588-6358

${ }^{3}$ Doutora em Administração pelo Programa de Pós-graduação da Universidade Federal do Rio Grande do Sul (UFRGS) - Brasil. Professora da Universidade Federal do Pampa-UNIPAMPA Rio grande do Sul - Brasil. E-mail: carolinafleck@unipampa.edu.br, ORCID: 0000-0002-1595$\underline{0100}$

${ }^{4}$ Versão inicial, apresentada no XXVI Encontro Nacional dos Cursos de Graduação em Administração, 25 a 27 de outubro de 2015, em Foz do Iguaçu/PR-Brasil. Texto revisado em 2019, após as considerações advindas das discussões e novas leituras.
} 


\section{Introdução}

O setor público exige de seus agentes, alguns requisitos e atributos peculiares, que são justificados pelo desempenho de atividades cuja competência de oferta é dever básico do Estado, como saúde, educação e segurança. Fazem parte deste grupo de agentes os professores que são servidores públicos, e que têm lei própria que aponta direitos e obrigações. No país, a lei que regula a carreira dos professores e dispõe sobre a educação nacional é a Lei Federal n 9.394 de 1996, mais conhecida como Lei de Diretrizes e Bases da Educação Nacional LDBEN.

Segundo o artigo $67^{\circ}$ da LDBEN, os sistemas de ensino devem promover valorização dos docentes, nos termos dos estatutos e planos de carreira assegurando que os professores desfrutem do direito ao aperfeiçoamento profissional e contínuo e caso necessário, do afastamento temporário e remunerado para este fim; que recebam o piso salarial profissional; que ocorra período destinado a estudos e planejamentos e que estes estejam incluídos na carga horária de trabalho; que tenham condições adequadas de trabalho (BRASIL, 1996). Porém, a realidade das instituições de ensino e de seus colaboradores podem ser distintas do que prevê a LDBEN.

Os servidores públicos estão expostos a outros fatores que assinalam a precarização do trabalho tais como: a privatização de estatais; a terceirização de departamentos; a deterioração das condições de trabalho; a culpabilização pelas falhas dos serviços; a inconstância ocasionada por câmbios políticos e rupturas; a sobrecarga de tarefas e o estereótipo da morosidade, aspectos que somados tendem a afetar a saúde dos servidores públicos (NUNES e LINS, 2009). Além disso, no caso do trabalho docente, os profissionais, no exercício de seu oficio se defrontam com múltiplos estressores psicológicos e sociais, alguns associados ao tipo de função que exercem e outros à conjuntura institucional e social em que trabalham o que ilustra, no momento, a grande sobrecarga de tarefas apontadas para o professor e que resulta no acúmulo de funções e sobrecarga de trabalho; que podem provocar estresse e enfermidades (LEVY, 2006).

O estresse e as doenças psicossomáticas vêm assolando uma parcela significativa da população economicamente ativa, no Brasil e no mundo. O relatório 
global lançado pela Organização Mundial da Saúde concluiu que os índices de quadros de depressão tiveram um acréscimo de 18\% entre os anos de 2005 a 2015, o que corresponde a 322 milhões de pessoas diagnosticadas com a doença em todo o mundo, com uma maior incidência de casos do gênero feminino (ONU, 2017). No Brasil, a depressão já atinge 11,5 milhões de brasileiros (5,8\% da população) ao passo que outros distúrbios e síndromes relacionados à ansiedade afetam mais de 18,6 milhões de pessoas, cerca de 9,3\% da população (ONU, 2017).

Muitas das patologias alvo de estudo da psicologia e da medicina do trabalho estão sensivelmente ligadas ao estresse, pois, o desgaste a que os indivíduos são expostos nos ambientes e nas relações laborais é fator crítico para o surgimento de enfermidades (CABRAL et al, 1997). A maioria dos servidores que se sentem desgastados é a mesma submetida à sobrecarga de funções e atividades; que exerce ações repetitivas e cansativas, o que implica em insatisfação e desânimo (FERREIRA e MENDES, 2001). Desse modo, o desgaste emocional impede que o trabalho proporcione prazer ou reconhecimento e acaba se tornando uma experiência penosa, caracterizada por angústia e sofrimento. Assim, as frustrações, pouco a pouco, são refletidas na saúde física e mental dessas pessoas (FERREIRA e MENDES, 2001).

Sintomas originários da sobrecarga de tarefas e das frustrações podem servir de gatilho para o desenvolvimento de enfermidades de cunho psicológico como depressões, síndromes, bipolaridade, ansiedade e transtornos obsessivos (JACQUES, 2005). Essas doenças tendem a afastar, precocemente, os servidores de suas funções, uma vez que estes podem ser considerados incapacitados para o pleno exercício de suas atividades (JACQUES, 2005). As estatísticas de trabalhadores que solicitam afastamento do trabalho por motivos de saúde que estão ligados ao estresse é cada vez maior (LEVY, 2006).

No Brasil, entre 2009 e 2015, quase 97 mil empregados requereram aposentadorias por invalidez em virtude de transtornos psicológicos e psiquiátricos, representando, os novos benefícios para os cofres públicos a importância de 113,3 milhões de reais por ano. Só no ano de 2016, 75,3 mil trabalhadores foram afastados em virtude do estresse, representando $37,8 \%$ de todas as licenças do ano (ÉPOCA NEGÓCIOS, 2016). Transtornos mentais e comportamentais, que incluem estresse, depressão, ansiedade, transtornos bipolares, esquizofrenia e 
transtornos mentais relacionados ao consumo de álcool e drogas contribuíram para que mais de 199 mil pessoas se ausentassem do trabalho e recebessem benefícios relacionados a estas enfermidades, o número de casos superou o total registrado em 2015 que havia sido de 170,8 mil casos (ÉPOCA NEGÓCIOS, 2016).

Esse cenário pode ser observado no setor público onde casos de servidores, em especial profissionais da educação, podem apresentar quadros de disfunções psicológicas que podem gerar inúmeros processos de licenças por doença ou aposentadorias especiais, e que pouco a pouco pode limitar a capacidade administrativa dos órgãos e entidades públicas, onerando o estado e contribuindo para que os serviços cuja prestação esteja vinculada ao Estado sejam considerados ineficientes e de qualidade questionável. Nesse sentido, além de ressaltar a importância da oferta de serviços públicos de qualidade, se torna imprescindível a observância das necessidades dos servidores, visto que não está em evidência tão somente o interesse comum, mas o bem-estar e a prevenção do adoecimento dos professores.

Um professor que presta um serviço eficiente deve ser, a priori, portador tanto de saúde psíquica quanto de equilíbrio emocional, deve ter condições ambientais mínimas para o exercício das atividades investidas em seu cargo ou função. Realidades contrárias a estas podem comprometer a qualidade do serviço prestado - o ensino, além da saúde desses profissionais. Em vista desta realidade, este estudo teve por pressuposto investigar quais as consequências geradas pelo aumento das patologias emocionais laborais na rotina de trabalho dos professores da rede pública de ensino do Rio Grande do Sul.

Esse estudo se caracterizou como qualitativo, tendo caráter descritivo sendo desenvolvido através do método de estudo de caso. Como método de pesquisa, o estudo de caso é empregado em diversas situações; para dar contribuições ao nosso conhecimento acerca de fenômenos de indivíduos, de grupos, de organizações, de sociedades e fenômenos políticos por exemplo (YIN, 2010). O método investiga fenômenos contemporâneos de maneira profunda e em contexto real, principalmente quando os fenômenos e contextos não são notoriamente claros. Uma investigação sob forma de estudo de caso geralmente enfrenta situações onde haverá variáveis de interesse em maior número em relação aos pontos de dados, 
porém, se beneficia do desenvolvimento anterior de proposições teóricas que orientam a coleta e a análise (YIN, 2010).

A fim de coletar os dados pretendidos, as técnicas de coleta de dados utilizadas na pesquisa foram o roteiro de entrevistas em profundidade e o grupo focal, estruturados a partir da teoria. A coleta de dados se deu com professores da rede pública estadual de ensino do Rio Grande do Sul. A escolha foi feita por conveniência. Uma entrevista do tipo grupo focal é aplicada com um reduzido grupo de pessoas, que geralmente compreende de 6 a 8 indivíduos e a duração média desse tipo de entrevista vai de 30 minutos a 2 horas (FLICK, 2009). O pesquisadorobservador deve ter empatia, deve saber ouvir e ser atento, além de estimular que os entrevistados se sintam envolvidos pela entrevista a fim de que emitam suas opiniões. A técnica de análise de dados utilizada foi a análise de conteúdo interpretativa (PATTON, 2002).

\section{O trabalho na satisfação e no adoecimento do ser humano}

Trabalho é toda e qualquer atividade que o ser humano executa e que resulta na transformação da natureza; tão ancestral quanto a obstinação que os seres humanos empregam em obter satisfação de suas necessidades, sobrevivência e a perpetuação das espécies (KRAWULSKI, 1998). Nesta ação, natureza e ser humano são coparticipes e o ser humano, com suas ações, promove, ordena e modera suas trocas materiais com a natureza ao mesmo tempo em que modifica a si mesmo e os outros seres humanos (MARX, 2012).

O trabalho é intercessor da integração social, pelo aspecto econômico e de subsistência, e pela cultura e simbolismos; exprime valor fundamental na construção da subjetividade, modo de vida e, portanto, na saúde dos indivíduos (MINISTÉRIO DA SAÚDE, 2001). Para além da sobrevivência, o trabalho é vital para a humanização dos indivíduos, no entanto, os excessos vinculados à exploração do indivíduo no trabalho acabam por levá-lo à objetificação e a falta de percepção de valor individual o leva ao adoecimento. O trabalhador por nada possuir, se assiste de seu trabalho para a subsistência e, nesse processo sua força de trabalho tende a ser objetificada (MARX, 2012). Não percebendo valor no que 
faz, deixa de perceber sua essência e o que entende por seu papel na sociedade (HELLER, 2016), adoece.

Mesmo em um contexto social de constante exploração do indivíduo através do trabalho, oriundo com a fixação do Modo de Produção Capitalista - MPC na sociedade, a construção social em torno do mesmo o tornou central na vida individual e na construção da sociedade. Tanto que o ser humano procura realização por meio do trabalho (OLIVEIRA e MAÑAS, 2004). O trabalho, nesse sentido, pode ser visto como fundamento da vida cotidiana. A perspectiva ontológica apontada por Marx; onde a base da identificação do indivíduo com o trabalho se dá para além da possibilidade de este estar empregado ou tornar-se acumulador de riquezas, mas sim, permeia toda a construção social de sentido de indivíduo e de ser social (MARX, 2012; HELLER, 2016).

E por envolver a percepção sobre si e sobre ser social, a relação dos indivíduos com o trabalho não é passível de tangenciar. Uma abstração na qual, Marx (2012), identificou o valor. Demonstrando que mesmo no processo de objetificação do trabalho, a percepção do trabalho como vital para o ser humano, inclusive em sua concepção mais básica pela relação com a necessidade de sobrevivência, é um conceito que não se dissipa. Conforme aponta Heller (2016) é valor tudo que explicita a essência humana. Quando a essência humana deixa de ser percebida e o indivíduo é alienado em um modelo simples de troca de mercadoria imposto pelo MPC, a percepção de valor se dissipa e o adoecimento no trabalho se torna elemento presente.

A teoria freudiana indica que são as capacidades de amar e trabalhar que compõem a saúde mental de um indivíduo e analisando-se esta teoria, de uma forma bastante ampla, nada fica desconexo, pois o amar compreende a reprodução da espécie, as emoções, os afetos, os laços entre família e amigos e o erotismo; o trabalhar por sua vez compreende a produção, a profissão, a posição social, o consumo e outros fatores. (ZANELLI et al, 2004). A vida humana gira em torno desses dois eixos e suas frustrações e anseios partem deles, onde com o amor se reproduz, e com o trabalho se produz (ZANELLI et al, 2004). O ser humano vive em busca da satisfação, que ocorre quando alcança o equilíbrio entre esses elementos anteriormente mencionados (ZANELLI et al, 2004). A realização por meio do 
trabalho depende de fatores que podem variar de indivíduo para indivíduo; das necessidades que cada um deles cria para si.

A atividade laboral e o valor ocupacional desempenhado por um indivíduo caracterizam papel crítico no seu senso de identidade, na sua autoestima e em seu bem-estar psicológico (MUCHINSKY, 2006). Todavia existem alguns fatores que podem ser classificados como primordiais para essa realização, e se o trabalho não vai bem, por vezes, a saúde do trabalhador também não vai (OLIVEIRA e MAÑAS, 2004). Trabalhadores comumente relatam suas frustrações causadas pela falta de recursos e oportunidades dentro das organizações; do ressentimento de prestar maiores contribuições à previdência; do acúmulo de tarefas e da baixa remuneração; estes sentimentos podem prejudicar as pessoas, além das organizações (OLIVEIRA e MAÑAS, 2004).

A literatura aponta que a satisfação no ambiente de trabalho é um fator crucial para que os indivíduos possam desempenhar seus afazeres de forma positiva. Portanto, a objetificação do trabalho da forma como o Modo de Produção Capitalista - MPC imprime às relações e suas condições, acaba impondo à sociedade um processo de insatisfação, que muitas vezes leva a uma perda no bem-estar das pessoas (MAX-NEEF, 1991), o que pode gerar adoecimento no trabalho, gerando problemas físicos e mentais.

De acordo com Heller, inspirada em Marx, a essência humana só existe se for constituída a partir de um conjunto de realizações associadas ao trabalho, sociabilidade, universalidade, consciência e liberdade, sendo assim, somente com a realização gradual e contínua destes aspectos é que tal essência se constitui. De forma alguma existindo como algo inato da sociedade humana (HELLER, 2016).

Nos estudos organizacionais, a Teoria das Relações Humanas, que data do ano de 1930, aponta argumentos de que a satisfação vem sendo pensada pelas organizações como um elemento diretamente vinculado à produtividade de seus colaboradores (MORO et al, 2013). Como forma de trazer para o trabalho, independente de qual seja, a realização individual, que depende de muito mais do que a sensação de produtividade, a Teoria das Relações Humanas falha, ao tentar incorporar a produtividade como percepção de valor ao indivíduo com seu trabalho.

Marx, ao analisar o trabalho e o trabalhador, "constata que, ao trabalhar, o trabalhador se exterioriza e se objetiva no produto de seu trabalho" (SPURK, 2005, 
p. 195), e por consequência encontra satisfação por essa exteriorização. É na abstração do trabalho que se encontra o valor, naquilo que não é possível tangenciar. Na alienação o trabalhador apenas encontra sofrimento e objetificação (MARX, 2012).

Os seres humanos vivem de ser, ter e estar. Ou seja, a satisfação é o fator motriz das atividades individuais, independente da época ou de costumes existentes (MAX-NEEF, 2011). Se as necessidades básicas dos indivíduos que trabalham nas organizações não forem atendidas ou mesmo se o ambiente de trabalho não for benéfico, os trabalhadores tendem a apresentar problemas e disfunções (OLIVEIRA e MAÑAS, 2004). E, esses problemas tendem a se tornar mais agudos com o passar dos anos (OLIVEIRA e MAÑAS, 2004).

$A$ ideia de que a atividade laboral pode se transformar em uma das principais motivadoras das enfermidades que assolam o ser humano não é uma teoria recente. $\mathrm{Na}$ Grécia antiga, pensadores como Hipócrates e Heródoto vinculavam o trabalho à saúde ou à doença. Ramazzini, médico italiano que viveu na idade média, descreveu doenças associadas ao trabalho ou a alguma ocupação como as lesões que os tipógrafos e escriturários da época apresentavam devido às jornadas intensas de trabalho e por movimentos repetitivos (JACQUES, 2005).

Na perspectiva do MPC, o trabalho é uma atividade penosa e que adoece (MARX e ENGELS, 2007). Com a prosperidade do capitalismo (fundamentos e perspectivas), pouco a pouco, as condições de trabalho se tornaram notoriamente muito mais precárias. Os trabalhadores se sujeitavam a salários miseráveis, jornadas intensas, trabalho infantil, condições insalubres e promiscuidade no ambiente de trabalho (JACQUES, 2005). Condições insalubres resultaram na fraqueza e mortalidade de muitos trabalhadores; houve o surgimento de mobilizações populares e intelectuais onde o Estado foi chamado a intervir nas condições trabalhistas, e só a partir de então surgiram as primeiras normas que pensaram melhores condições laborais (JACQUES, 2005). Com os movimentos sindicais, muitos avanços ocorreram e as condições de vida e de trabalho tiveram avanços significativos (JACQUES, 2005).

Atualmente, a OMS conceitua saúde muito além da ausência de enfermidades físicas, pois só é presumível existir plena saúde quando existe total bem-estar físico, mental e social (OPAS; OMS, 2016). Muitos aspectos podem pôr 
em risco a saúde mental dos indivíduos tais como repentinas mudanças sociais, agressões, más condições laborais, episódios de segregação por raça ou gênero, inobservância dos direitos humanos, hábitos de vida prejudiciais e entre outros (OPAS; OMS, 2016). A promoção da saúde mental abarca a adoção de ações que consintam aos indivíduos tomar e cultivar estilos de vida saudáveis (OMS, 2016).

Mesmo a realização e bem-estar estando atualmente em voga, arbitrariamente, as pessoas estão adoecendo mais. Estresse, ansiedade, informações em demasia, inaptidão para lidar com emoções e entraves profissionais fazem com que os indivíduos se sintam preocupados em demasia (OLIVEIRA e MAÑAS, 2004). Pessoas preocupadas não costumam trabalhar bem; a maior parte de sua energia é concentrada na tentativa de domar suas emoções, logo, podem apresentar o desenvolvimento de patologias psíquicas (OLIVEIRA e MAÑAS, 2004).

$\mathrm{O}$ ato de adoecer mentalmente pode ser classificado como um efeito colateral de sucessivas frustrações; precárias condições laborais e altas cargas de exigências, condições previsíveis causadoras de efeitos distintos entre os trabalhadores (DAVIDOFF, 2001). Existem inúmeras pesquisas sobre a origem desses distúrbios que se enraízam no estresse, tais pesquisas supõem que as causas vão desde fatores genéticos, de desenvolvimento, naturais, psicossociais e fisiológicos, a fatores ambientais, fatores estes que podem agir em conjunto ou isoladamente, contribuindo para o surgimento dos distúrbios (DAVIDOFF, 2001).

O termo psicossomático confere ao ser humano um olhar do todo, sendo composto por mente e corpo que interagem com o meio social; onde esses elementos são considerados inseparáveis e interdependentes. (LIPOWISKI, 1984). Os transtornos emocionais relacionados ao trabalho resultam de contextos de trabalho em interação com o corpo e aparato psíquico dos indivíduos (MINISTÉRIO DA SAÚDE, 2001). Algumas enfermidades associadas à atividade profissional demandam, motivadas por sua gravidade, temporários ou permanentes afastamentos do trabalho, como parte do tratamento e/ou pela necessidade de pausar a exposição aos fatores de risco presentes nas organizações (MINISTÉRIO DA SAÚDE, 2001). As principais patologias associadas ao trabalho são: Estresse; Síndrome de Burnout; Depressão e Bipolaridade. Suas características principais são apresentadas no Quadro I. 
Quadro 1: Patologias do Trabalho

\begin{tabular}{|c|c|c|}
\hline Patologia & Características & Autores de Referência \\
\hline Estresse & $\begin{array}{l}\text { Tensão; Frustração; Exaustão Emocional - } \\
\text { associados a situações negativas no trabalho. Pode } \\
\text { acarretar sintomas físicos. }\end{array}$ & $\begin{array}{l}\text { Davidoff, 2001; Levy, } \\
\text { 2006; Morin e Aubé, } \\
2009 .\end{array}$ \\
\hline $\begin{array}{l}\text { Síndrome de } \\
\text { Burnout }\end{array}$ & $\begin{array}{l}\text { Conhecida como Síndrome do Esgotamento } \\
\text { Profissional - tensão emocional e estresse crônico; } \\
\text { Profissionais que atuam nas áreas de saúde, } \\
\text { educação, recursos humanos, assistência social, } \\
\text { bombeiros ou policiais, correm risco maior de } \\
\text { desenvolver a síndrome. O principal sintoma é a } \\
\text { sensação de esgotamento físico e emocional } \\
\text { Surgem também alterações físicas como: } \\
\text { enxaqueca, cansaço, sudorese, palpitação, pressão } \\
\text { alta, dores musculares, insônia, crises de asma e } \\
\text { distúrbios gastrintestinais. }\end{array}$ & $\begin{array}{c}\text { Levy, 2006; Varella, } \\
2017 .\end{array}$ \\
\hline Depressão & $\begin{array}{l}\text { Caracterizada por tristeza intensa e forte ausência de } \\
\text { esperança. Um indivíduo que se sente abatido, } \\
\text { desanimado e desmotivado para a vida e suas } \\
\text { atividades cotidianas. Consequentemente, os } \\
\text { deveres e as tarefas importantes para o indivíduo vão } \\
\text { sendo negligenciadas e ocorre isolamento. O gênero } \\
\text { feminino pode ser mais suscetível à doença em } \\
\text { virtude da oscilação hormonal. Sintomas: alteração } \\
\text { de peso; pensamentos suicidas, culpa, insônia e } \\
\text { dificuldade de concentração. }\end{array}$ & $\begin{array}{l}\text { Davidoff, 2001; Varella, } \\
2017 .\end{array}$ \\
\hline Bipolaridade & $\begin{array}{l}\text { A característica mais acentuada é a incidência de um } \\
\text { revezamento, por vezes, repentino, de episódios de } \\
\text { depressão com episódios de euforia e intervalos } \\
\text { assintomáticos. Existem categorias, conforme } \\
\text { intensidade e manifestações, porém o mais agudo é } \\
\text { o Transtorno bipolar Tipo l; nele ocorrem episódios } \\
\text { de mania e depressão; seus sintomas e conduta } \\
\text { geralmente comprometem relacionamentos, } \\
\text { desempenho profissional, posição econômica e } \\
\text { segurança do paciente e das pessoas que com ele } \\
\text { convivem. É um transtorno potencialmente } \\
\text { incapacitante, mas que pode ser tratado com sucesso } \\
\text { (medicação e terapia). }\end{array}$ & $\begin{array}{c}\text { Lara, 2004; Varella, } \\
2017 .\end{array}$ \\
\hline
\end{tabular}

Fonte: elaborado pelas autoras com base na literatura.

\section{Apresentação e discussão dos resultados}

Foram entrevistadas três professoras da rede pública estadual de ensino, de diferentes escolas do estado do Rio Grande do Sul seguradas pelo Instituto Previdenciário do Estado - IPE que ao longo de suas trajetórias de docência vivenciaram problemas no ambiente de trabalho e em consequência destes ou outros acabaram por apresentar doenças emocionais. Entre as entrevistadas, uma ainda exerce a atividade de docência, outra está com delimitação de função e a 
última está em delimitação de função e processa o Estado na pessoa da Coordenadoria Regional de Educação. As entrevistas contêm relatos da vida pessoal e funcional das professoras. A fim de preservar a imagem das profissionais as nomearemos usando flores.

Hortência, a primeira professora entrevistada, é concursada vinte horas em um município e vinte horas no Estado. Apresenta quadro bipolar e relata ter "medo de entrar em sala de aula”. Conta que após retornar de licença saúde, gozada para realizar cirurgia, retomou as atividades onde trabalhava e foi a partir de então que os primeiros problemas começaram a surgir. Se deparou com uma turma com vários alunos com problemas de conduta e mau comportamento e passou a ter dificuldades com o exercício da docência. Na tentativa de amenizar os problemas, a direção da escola estadual a encaminhou para setores administrativos como secretaria e biblioteca e a municipal a designou para o cargo de professora substituta nos anos iniciais do ensino fundamental, mas Hortência não se adaptou a nenhuma das funções. Relata que os problemas eram vivenciados em ambas escolas.

Após dois anos, a diretora da escola municipal solicitou ajuda psiquiátrica junto à instituição municipal que trata de saúde mental. Foram diagnosticadas depressão e bipolaridade, seus laudos apontam que ela não tem aptidão para trabalhar com crianças. Hortência está em tratamento psiquiátrico e psicológico desde a época até os dias de hoje. Seu tratamento é custeado pelo município. Atualmente se encontra com delimitação de função nas duas escolas. Ao ser questionada sobre a oferta de tratamento médico do IPE, a entrevistada relata que "é tudo muito demorado" e que, portanto, só utiliza o tratamento municipal. Expõe que "queria nunca ter saído da sala de aula, queria perder o medo de encarar uma turma, ser como era antes, cheia de disposição". Finaliza dizendo que não quer tirar licenças, pois o convívio com os colegas e o dia-a-dia da escola a fazem bem e que em casa, se sente deprimida, então vai trabalhar. Trabalha na biblioteca, porém conforme recomendações médicas, acompanhada de outros profissionais.

Os relatos de Hortência vão ao encontro do que a literatura aponta sobre o adoecimento mental oriundo de sucessivas frustrações; precárias condições laborais e altas cargas de exigências, condições previsíveis causadoras de efeitos distintos entre os trabalhadores (DAVIDOFF, 2001). 
A professora Rosa, trabalha quarenta horas no Estado. É professora de Educação Especial. Relata que seus primeiros problemas surgiram quando a Coordenadoria Regional de Educação - CRE fechou a classe especial em que dava aula e a transferiu para uma escola em outro município, porém, designando a ela a regência de uma classe regular. Rosa foi transferida para escolas que não tinham classe especial, contrariando sua formação e titulação em concurso. Conta que a última escola para a qual foi transferida tinha pouquíssimos recursos com turmas multisseriada, e a classe especial funcionava junto ao pequeno laboratório de informática, a estrutura era muito precária. Relata que fazem muitos meses que não recebe suas funções gratificadas, e que a questão financeira a preocupa muito. Com relação ao exercício de seu trabalho e sobre sua transferência e condições da nova escola, Rosa declara que não queria ter saído da escola onde trabalhava há doze anos, não só por vínculos com os colegas, mas pelo ambiente de trabalho e o trabalho que desenvolvia com crianças e adolescentes com deficiências.

Sobre a perda do vínculo com a antiga escola, coloca que a desmotivou e gerou frustração e que não fosse o apoio familiar teria ficado "mais doente". Conta que chorava muito e chegou a usar remédios para dormir pois andava deprimida e estressada, mas pensa que conseguiu se estabilizar emocionalmente. Recentemente surgiu a oportunidade de trabalhar em uma escola de surdos em outra cidade, Rosa pediu transferência para outra região do Estado e acredita que muito em breve sua remoção aconteça. Relata que está empolgada com a transferência e que quer ter novos desafios. A professora destaca que o suporte dado pela CRE as vezes é falho, e relaciona isso tanto aos problemas administrativos que enfrenta por seu salário quanto por ser designada a vagas para as quais não tinha habilitação, o que destoa da lei. Coloca que o atual sistema da CRE vem deixando a desejar, pois além da burocracia e das falhas na comunicação, ainda existe uma grande sobrecarga de tarefas por parte das próprias pessoas que trabalham na CRE e que muitas destas pessoas que hoje trabalham em setores administrativos estão lá justamente por motivo de saúde, física ou mental, por já não conseguirem exercer a docência.

O caso de Rosa pode ser exemplo do que a literatura aponta sobre o estresse ocupacional, onde sentimentos de tensão, frustração e exaustão emocional, relacionados a situações negativas do trabalho tornam o indivíduo suscetível ao 
adoecimento e a perda do vínculo de identidade com o trabalho (MORIN e AUBÉ, 2009).

A professora Camélia trabalha vinte horas no Estado e, atualmente, se encontra afastada. Há alguns anos enfrenta problemas no ambiente de trabalho. Relata que trabalhava como professora de Educação Especial na capital, há cinco anos, quando, por motivos particulares, resolveu pedir transferência para outra cidade. Sua solicitação foi atendida e sua transferência foi aprovada, porém, quando assumiu na escola a que foi designada, constatou que a escola não contava com classe especial, e que havia ocorrido um erro administrativo.

A professora foi até a CRE e a informaram que nas escolas da região não existiam vagas para educação especial e que o erro tinha sido cometido pela CRE da capital e que esta não tinha mencionado que a vaga era específica para deficiência mental. Camélia foi instruída a permanecer na escola até que providências fossem tomadas. Relata ter ficado várias semanas aguardando providências e que ocorreu uma greve nas escolas estaduais de todo o Estado o que agravou seu tempo de espera. Camélia declara que se propôs a ajudar no que a escola precisasse enquanto esperava as resoluções da CRE. Passou a auxiliar na biblioteca, substituindo aulas na ausência de professores e servindo merenda para alunos.

Destaca que talvez esse tenha sido o seu erro, pois os funcionários da escola passaram a pedir que ela fizesse serviços de limpeza e manutenção que competem à zeladores e merendeiras, e acredita que a partir do momento em que se negou, alegando que era professora o ambiente "ficou pesado" e não houve interesse da direção de que o caso fosse solucionado. Camélia relata que muitos meses se passaram e nada aconteceu, não tinha vontade de ir à escola, pois "ou ajudava nos serviços ou não fazia nada". Desenvolveu problemas de estresse e depressão e em uma crise grave da doença se afastou em licença saúde pela primeira vez. No meio do tratamento ficou grávida.

Quando de seu retorno Camélia conta que teve conflitos com colegas, que foi insultada e "taxada de preguiçosa". Relata que foram os piores meses de trabalho. Passados vários meses e com a substituição de cargos na CRE (devido as eleições para governador e à troca de governo), Camélia diz que finalmente sua situação foi solucionada. Atualmente processa administrativamente o Estado pelo 
caso, pela demora na tomada de soluções e pelo salário reduzido significativamente devido ao cancelamento do pagamento das funções gratificadas.

Camélia submeteu-se ao que era demandado a ela como forma de apoiar a instituição, na expectativa de que a coordenadoria de educação resolvesse seu caso e pudesse retornar ao trabalho que tanto gostava de desenvolver. Fica evidente no caso de Camélia a alienação relacionada ao trabalho, onde passou a ser vista apenas como um meio. Deixou de perceber o trabalho como uma realização para perceber como sofrimento e com adoecimento (MAX-NEEF, 2011; OLIVEIRA e MAÑAS, 2004).

O grupo focal foi realizado com seis professoras que exercem cargos de chefia em cinco diferentes escolas da CRE, sendo uma diretora, três vice-diretoras e duas supervisoras de ensino que igualmente serão denominadas como flores e as escolas serão aqui representadas por nomes de cores.

Quando questionadas acerca das patologias emocionais mais frequentes entre os servidores, percebidas ao longo dos anos nas escolas em que trabalham, as professoras relataram nem sempre terem acesso aos laudos médicos dos profissionais de suas escolas, por se tratar de questão administrativa inerente às CREs e ao IPE. A perícia somente informa as escolas o período em que o profissional ficará afastado. Porém, tomam conhecimento de maneira informal e destacam que a depressão, a bipolaridade e a síndrome do pânico são as mais frequentes, principalmente entre professores do sexo feminino. O grupo aponta que as mulheres são mais propensas ao desenvolvimento de quadros de depressão, sendo que este entendimento está de acordo com o proposto por Varella (2017). Concluem que as professoras dão atenção à casa, filhos, trabalho, alunos e entre outros, o que demanda um nível de comprometimento diferente dos homens.

A professora Girassol, da escola Amarela, acrescenta que no ensino fundamental o número de professoras é muito maior. As docentes são unânimes ao declarar que todas as escolas têm algum caso de afastamento de professores ou profissionais por doenças, sejam psíquicas ou não. Considerando a fala da professora Margarida, da escola Azul, se entende que quando um professor enfermo retorna ao ambiente de trabalho, na quase totalidade dos casos, este profissional apresenta laudo médico atestando que o desempenho de suas atividades deve ser restrito. Porém, os laudos de profissionais cujas atividades 
devem ser delimitadas, geralmente não são claros, e fica a cargo da equipe diretiva avaliar que atividades esse profissional pode ou não exercer e realocá-lo em um novo setor. A professora Tulipa, da escola Verde, reitera, colocando que professores delimitados não devem manter contato com alunos, e neste caso ficam como apoiadores, desempenhando na maioria das vezes somente atividades de cunho administrativo, todavia sempre na presença de outros profissionais.

Margarida relata que quando um professor apresenta atestado, o setor de supervisão tenta preencher os horários vagos e turmas que temporariamente se encontrem sem regência de classe com outros professores, o que quase sempre é uma tarefa difícil, pois não existe um cargo de professor substituto e os demais professores, na maioria quase absoluta das vezes, já estão com sua carga horária lotada. Então, em algumas ocasiões, os professores que estão em cargos administrativos veem obrigados a entrar dar aula para suprir a necessidade, que tem caráter de urgência, até que se consiga um profissional por meio de contato com outras escolas ou até que a CRE envie um professor para substituir o enfermo, o que conforme Margarida e as demais professoras raramente acontece, principalmente quando a licença usufruída pelo docente é de menos de trinta dias. A professora Bromélia, da escola Vermelha, completa dizendo:

tem que ir se virando. Quando as professoras entram com laudo psiquiátrico tu já sabe que ela não vai retornar em seguidinha, que vai renovar. Porque normalmente renova, renova e tu como direção fica à mercê daquela situação.

Ao serem questionadas sobre as possíveis causas do adoecimento dos profissionais e se percebem aumento no número de casos ao longo dos anos, Margarida e Girassol ressaltam que vários fatores somados contribuem para que se adoeça. Margarida coloca que a sobrecarga de função a qual os docentes são submetidos é muito desgastante. Enquanto que Girassol aponta que a carência na educação dos alunos, que muitas vezes não tem um lar estruturado e boas referências no âmbito familiar são cada vez mais comuns, e que a cada ano se tem mais alunos com esse perfil.

Lidar com estas crianças e adolescentes é muito estressante. $\mathrm{O}$ professor acaba por virar uma extensão da família, principalmente o professor que trabalha com crianças". Girassol corrobora com a afirmação anterior: "a gente virou pai, a mãe, conselheira, professora, esposa, marido, mãe, tudo! (Girassol) 
Margarida complementa "o porto seguro somos nós ali. E se a gente não tem estrutura pra segurar, aí como é que vai ser?! Aí virá o caos né?!".

Do ponto de vista da equipe gestora, Bromélia coloca:

nossa função enquanto gestão é muito mais mediar, mas daí se tu não tem uma boa estrutura, como é que tu vai ofertar essa mediação? É complicado também!", Orquídea completa "tem todo esse histórico, essa questão de família. Tu olhar o ser humano que tá ali profissional, mas que acima de tudo é um ser humano, tem toda uma demanda em cima de nós. Então assim, gerir todos esses lados é muito difícil.

Todas as entrevistadas concordam que a escola desempenha um papel que deveria ser da família. Tulipa expõe que o que desencadeia as doenças "são problemas externos, mas é claro que um somatório de questões dentro da realidade escolar acirra esses problemas", falando sobre funcionários de cozinha e limpeza, Tulipa completa:

as funcionárias têm sobrecarga mesmo. $\mathrm{O}$ trabalho delas é árduo, difícil e com os professores não, é o somatório, talvez de um contexto pesado que envolve o familiar, pessoal e o profissional e mais coisas".

Bromélia, por sua vez, aponta que a demanda de tarefas é cada vez maior Orquídea, da escola Verde, diz que "o trabalho da equipe diretiva é cansativo" e Margarida ressalta "a tendência é tu correr cada vez mais, é tu acelerar cada vez mais". As professoras concluem que o profissional adoece porque está sobrecarregado e muitas vezes preocupado. Tulipa coloca:

é interessante ressaltar que todos que apresentaram problemas na escola, tanto professores quanto funcionários, os problemas tendem a se acirrar. Piorar ao longo dos anos. Em nenhum dos casos da escola houve melhora, só piorou!

As docentes colocam que o profissional que se afasta para tratamento melhora, mas ao retornar para a escola apresenta regressões e geralmente afastarse-á inúmeras vezes até que se aposente por saúde ou por idade. Referem que além dos casos de doenças diagnosticadas, existem profissionais que por vezes apresentam instabilidade emocional, pois sofrem desgaste. Alegam que estes profissionais reclamam, se queixam, mas que trabalham diariamente. A professora Azaléia, da escola Laranja, relata:

eles pegam a gente de cantinho e contam o caso, a gente fica numa situação, sabe que se ele sai vai ficar com um problema sério, vai assumir quem naquela parte que ele não vai fazer, sabe?!" Girassol 
finaliza dizendo "não temos disponibilidade de gente pra substituição, não adianta! E não se pode desamparar o aluno!

Quando questionadas sobre como fica a rotina de trabalho dos professores remanescentes e que também substituem temporária ou definitivamente os professores afastados, a professora Tulipa responde "sobrecarregamos os outros profissionais. Na emergência, colocamos gente de setor em sala de aula, os colegas ficam com muita carga horária, acima da carga horária porque não tem alternativa!". Conforme os relatos, o Estado não consegue repor em tempo hábil um profissional para suprir a falta de outro enfermo, sanar a ausência dos profissionais faltantes requer empenho da escola e seus profissionais; com arranjos as lacunas são temporariamente sanadas. Essa inconstância acaba por comprometer a qualidade do ensino. Orquídea, ao se referir aos arranjos feitos para a substituição das aulas: "colocar alguém isso se torna fácil pro Estado, aí resolveu o problema!", Bromélia justifica, "mas a gente tem que garantir o ano letivo".

As professoras ressaltam que no mínimo se estraga o planejamento do professor que vai substituir e do que é substituído, isto quando não atrapalha o dos outros professores que se revezam ou antecipam suas aulas, pois às vezes um mesmo professor trabalha em várias escolas. O ritmo das turmas é danificado e a aprendizagem do aluno é prejudicada, comprometendo a qualidade. Bromélia conclui:

\begin{abstract}
tu acaba desestimulando o aluno, principalmente o adolescente dos anos finais do ensino fundamental e médio. Desestimulando com a falta do profissional, porque eles tão num ritmo de trabalho, isso prejudica em resumo a aprendizagem do aluno." Azaleia ressalta "quando começa a faltar um colega, isso dá um desgaste tamanho no grupo e ao mesmo tempo no aluno. Mesmo que gostando, ah, não quero mais ter aula, ah, de novo subir período, o aluno sente! $\mathrm{A}$ gente perde a credibilidade da escola.
\end{abstract}

As professoras relatam que a realidade escolar não permite à direção o desempenho exclusivo de atividades administrativas, pois a demanda é diversificada e são muitos alunos e turmas para atender.

As professoras são questionadas se 0 ano letivo inicia com o número de profissionais necessários para que se possa atender a demanda. Em resposta, a maioria afirma que raramente o quadro inicia completo, sempre há lacunas. Bromélia justifica: "em função dessas licenças nós temos muita carência de recursos humanos, hoje vamos encerrar o ano com carência de funcionários $e$ 
professores". Colocam ainda que não é dever da direção alocar os professores na escola, pois na CRE existe uma central informatizada que reúne os dados das escolas da região, onde diretores encaminham os dados para que a Coordenadoria insira os recursos humanos em um sistema de informação e possa fazer a gerência de pessoal. Acerca do suporte dado pelo IPE, pela Coordenadoria Regional de Educação e pela Secretaria Estadual de Educação a professora Bromélia relata:

Com o IPE a gente nem se envolve, é com o servidor né!! A coordenadoria é quem está mais próxima a nós. Hoje nós temos um sistema e nesse sistema que a gente lança toda a distribuição da carga horária do professor lá, no RHE né?! [...] Só que a gente não consegue atualizar o RH! Então fica aquele impasse, bom dia " $x$ " 24 de fevereiro iniciam as aulas, tem que iniciar de qualquer jeito, com lacuna ou sem lacuna! Então a coisa já sai incompleta, digamos assim com um formato, com o número de lacunas que a gente tem, se um professor vem a faltar ou tirar uma licença saúde ou qualquer outra coisa que seja, o problema acaba sendo maior ainda! Então, talvez assim, claro que na Secretaria de Educação a gente não tem muito acesso porque na verdade quem nos representa é a Coordenadoria. Então assim falta essa, eu acho que falta, deixa muito a desejar sim o suporte. A gente necessitava de uma coisa que fosse mais ágil, nem coloco culpa nas pessoas, não é isso acho que o sistema é fragilizado.

As professoras colocam que os dados inseridos no programa deveriam circular de forma que todas as escolas tivessem acesso e destacam que certamente a implantação de um sistema mais ágil ainda vai demorar a acontecer. Atualmente as escolas entram em contato umas com as outras, verificando a ocorrência de casos de professores com carga horária reduzida e em caso afirmativo o profissional é cedido mediante acordo com a outra escola. Assim são feitos os arranjos para agilizar o processo. A professora Girassol contribui "somos de cinco escolas e olha tudo que a gente tá falando, se tu considerar que a Coordenadoria tem cento e quatro escolas, pra poucas pessoas atendendo. Então assim o sistema é fragilizado". As professoras destacam ainda que é comum receberem ligações da CRE indicando que professoras que trabalham vinte horas no Estado assumam quarenta horas sendo que muitas vezes essas profissionais também trabalham no município.

Relatam que também ocorre da CRE designar profissionais em delimitação de função conforme indicação de laudos médicos para assumir turmas. Tulipa que é diretora de escola, relata ter recebido essa ordem da Coordenadoria e justifica a sua resposta negativa à CRE dizendo: "como é que eu vou botar essa professora, 
ela tem depressão, tá em delimitação de função na biblioteca. Sabem que não pode e aí eles querem que tu bote mas como é que eu vou tirar da biblioteca essa professora, e a lei?". As professoras colocam que os profissionais com delimitação de função e com problemas emocionais contam para o Estado como recurso humano em plena atividade. Margarida contribui eu vejo como uma coisa muito grave, no somatório de profissionais ele conta como recurso, como os outros. No somatório da montagem de quadro, ele conta", Tulipa complementa colocando: "ele não é considerado funcionário ou professor com problema de saúde, mesmo tu incluindo no sistema na hora de colocar lá, aí eles dizem ah, mas tu tens cinco! Eu tenho cinco, mas cinco que não estão em pleno trabalho!". O que pode indicar que o Estado deixa de alocar profissionais para determinado setor ou disciplina porque o sistema aponta que já existe profissional ocupando o cargo ou vaga.

Colocam que os profissionais doentes que regressam às escolas raramente retornam para função que desempenhavam antes. A maioria afirma que estes profissionais não se recuperam a ponto de desempenhar novamente suas antigas funções. Tulipa diz "aqui na escola nenhum caso, todas que tiraram laudo voltaram delimitadas e não voltaram pra o lugar de origem, estão em setores há anos", Orquídea complementa "tem uma professora que faz dois anos a outra faz uns quatro ou cinco anos já, também que está em setor e as funcionárias tem algumas".

Questionadas sobre a quem compete a definição dos critérios para delimitação e sobre qual profissional avalia que atividades tem ou não caráter de delimitação de função, as professoras respondem que são a perícia médica e o Estado na pessoa da Coordenadoria respectivamente. Margarida responde "vem um documento do Estado escrito delimitação de função, de dia tal a tal. Vem uma descrição, mas nem sempre é uma coisa clara, quase nunca é. A gente tem que conversar com o funcionário ou professor, ver como tá a situação e ir monitorando dessa forma". Sobre a falta de clareza dos documentos encaminhados, a professora e como a equipe diretiva procede, a professora Girassol relata "a gente fica procurando um lugar, tentando achar pra encaixar aquela pessoa delimitada, mas, como muitas já falaram, ela conta no quadro da escola como se trabalhasse naturalmente".

Quando questionadas sobre em quais setores essas pessoas mais são alocadas, as professoras respondem que existem profissionais com função 
delimitada auxiliando na secretaria porque é um local onde não se tem circulação de alunos, nas bibliotecas auxiliando as bibliotecárias quando a escola conta com esse tipo de profissional, no setor de fotocópias e até mesmo nos corredores controlando a circulação de alunos. Sobre os funcionários com função delimitada, as professoras relatam que designam os locais mais fáceis de limpar e que exigem o mínimo de esforço como laboratórios de informática, por exemplo, e devido a um número significativo de profissionais de limpeza e serviços gerais com delimitação de função, geralmente faltam profissionais para efetuar a limpeza das salas de aula, o que tende a sobrecarregar funcionários sadios.

As professoras destacam que procuram conversar com sua equipe, para que possa ter compreensão e para que possa cooperar com os funcionários e professores enfermos. Porém existem alguns professores que se queixam dos profissionais doentes e passam a surgir pequenos conflitos internos. Orquídea comenta "sobra mais uma vez para a equipe diretiva, temos que mediar os conflitos". Sobre a recuperação e retorno dos colegas professores afastados, Tulipa justifica "os problemas são todos bem crônicos realmente. Tem casos que a gente nem tem como ter dúvidas que a pessoa tem problemas". As professoras comentam que existe falta de cooperação por parte de alguns colegas.

No tocante aos professores enfermos e se estes conseguem se aposentar em regime especial por doença ou permanecem no âmbito escolar, colocam que em quase todos os casos, os professores passam anos e anos trabalhando com delimitação e geralmente só se aposentam quando completam o tempo de serviço, o que prejudica todo um trabalho da escola pelo fato de contarem como recurso humano efetivo. As entrevistadas entendem que podem até existir casos de docentes que se trataram e que se recuperaram, porém desconhecem casos dessa natureza na cidade. Destacam que geralmente as pessoas esperam anos e anos até que possam se aposentar.

A respeito dos procedimentos para aposentadoria no Estado, que não os por tempo de serviço e idade, as professoras colocam que não sabem dizer ao certo quais são, pois são raras as ocorrências e que em caso de enfermidades os valores da aposentadoria são calculados proporcionalmente aos anos trabalhados pelo profissional. A professora Tulipa conta o caso de uma professora que passou anos delimitada e se aposentou vários anos depois por apresentar problemas de saúde, 
porém seus rendimentos foram calculados proporcionalmente aos anos do exercício da docência e a professora em questão teve que apelar para a justiça para garantir seus direitos, porém a professora não sabe dizer ao certo se a professora conseguiu que novo cálculo fosse realizado.

As professoras destacam que há relatos de docentes que trabalham concomitantemente no Estado e município e que conseguem se aposentar pelo município, porém no Estado ou permanecem por anos com licenças saúde ou em atividades delimitadas e raramente se aposentam. A professora Tulipa declara: "não entendo como é que uma perícia médica no mesmo estado, na mesma função, uma municipal e a outra estadual. O município afasta uma pessoa por problemas de depressão, porque que ela está impossibilitada de atuar por desequilíbrio emocional, e o Estado diz que a mesma pessoa tem que voltar imediatamente por que deve trabalhar delimitada na escola. E a gente tem ciência que ela não tem condições. Então quer dizer, nós também enfrentamos um problema médico, de saúde e isso é seriíssimo!"

Questionadas sobre como fica a motivação da equipe diretiva com todos os conflitos, falta de pessoal e sobrecarga de tarefas, as professoras respondem que tem esperança, apesar da carência de recursos humanos e por vezes de recursos materiais que enfrentam, elas relatam se empenhar e crer que a situação da educação um dia irá melhorar. Porém, descrevem que em algumas escolas as pessoas que exercem cargos em equipes diretivas desistem do cargo e retornam para a sala de aula, alegando geralmente desgaste, falta de reconhecimento e motivação. Bromélia narra: "nós temos um compromisso, temos que acreditar que um dia as coisas vão andar", Margarida por sua vez expõem "a gente assumiu um compromisso com a profissão e a gente não pode deixar a peteca cair! Temos que tentar fazer alguma coisa pelos nossos alunos".

As docentes contam que desempenhar um cargo de gestão é geralmente difícil e demanda muita responsabilidade e dinamismo, apontam que sentem falta de um psicólogo, um assistente social ou um terapeuta, atuando dentro da escola para que elas possam ter um suporte para lidar com alunos e colegas docentes. Relatam que esses profissionais, assim como dentistas e médicos já estiveram presentes em algumas escolas estaduais há anos, sob forma de uma política de 
governo, e concluem dizendo que atualmente as escolas do município contam com esses profissionais.

É perceptível na pesquisa que as relações de trabalho, mesmo em uma profissão como a docente, onde o propósito é a educação e que tem como objetivo a formação de cidadãos que o MPC permanece como pano de fundo. As experiências de adoecimento no trabalho relatadas demonstram que quando as docentes não tiveram condições de permanecer desenvolvendo plenamente suas atividades de sala de aula foram colocadas para desenvolver outras atividades, que já estavam de certa forma desassistidas, uma vez que seu trabalho passou a ser cobrir uma outra área da escola, como forma de permanecerem sendo úteis e ativas no sistema educacional. Bem como, para as docentes, a centralidade do trabalho e a importância do mesmo como forma de satisfação própria permanecem e o desejo de retornar a atividades que geram valor para si permanecem (MARX, 2012; MAXNEEF, 2011).

O trabalho para estas mulheres deixou de ser significativo para ser alienado, mas não deixou de ser central em suas vidas. Haja vista que o seu adoecimento, é também consequência do trabalho. Os relatos reforçam o que Oliveira e Mañas (2004) argumentam de que a construção da sociedade acontece com centralidade do trabalho para os indivíduos sendo a força motriz dessa construção. Reforçando também a perspectiva ontológica do trabalho, onde a identificação do indivíduo se dá para além da possibilidade de este estar empregado ou tornar-se acumulador de riquezas, mas sim, permeia toda a construção social de sentido de indivíduo e de ser social (MARX, 2012; HELLER, 2016).

\section{Considerações finais}

Por meio da análise foi possível identificar que as consequências do adoecimento de docentes são, de um modo geral, o desgaste da equipe diretiva da escola e a sobrecarga de tarefas dos professores remanescentes. A equipe diretiva acaba tendo que desempenhar funções diferentes das que se relacionam às suas atribuições para fazer arranjos e minimizar o problema da falta de professores. Os

professores que permanecem trabalhando nas escolas que enfrentam o 
afastamento de professores doentes acabam por ter de fazer a compensação da ausência dos professores afastados.

Tais aspectos acabam por contribuir para a precarização da educação e para uma maior fragilidade do sistema educativo como um todo. A transformação do trabalho em mercadoria, especialmente na área da educação, e a precariedade das condições de trabalho são algumas das consequências da construção social do sistema capitalista. Fato que acaba por levar docentes ao adoecimento, uma vez que não conseguem desenvolver suas atividades com qualidade. Tampouco logram estabelecer um contato mais próximo e qualitativo com os alunos e menos ainda envolvê-los em um processo de ensino-aprendizagem adequado.

A rotina de trabalho do professor é exaustiva. Como forma de gerar economia para a máquina pública, em termos de alocação de recursos humanos, o estado diminui o contingente de contratações. Então, para que o número de professores concursados e anteriormente contratados já existente nos quadros - e defasado consiga atender a demanda, as salas de aula se veem com um número cada vez maior de alunos. Mais uma vez, o trabalho do professor e a aprendizagem dos alunos se veem prejudicados.

Se percebe que a maioria dos profissionais leciona em duas ou mais escolas, como forma de aumentar a renda e garantir o sustento, próprio e, da família. Um dos motivos pode ser o valor dos salários pagos para os profissionais da educação ainda são considerados baixos. Eles geralmente têm sua carga horária superlotada. O deslocamento entre escolas onde os professores trabalham demanda tempo. Esses fatores somados à múltiplos estressores psicológicos e sociais de mesmo modo estimula o adoecimento dos docentes. Além de jornadas de trabalho exaustivas, também ocorre o acúmulo de tarefas e desempenho de funções extras o que resulta em sobrecarga de trabalho, implicando em maior carga de estresse.

Entre as patologias emocionais mais comuns, a depressão tem lugar de destaque, principalmente entre profissionais do gênero feminino. Esse quadro se justifica devido ao fato de que, conforme os relatos, além das docentes serem maioria nas escolas, principalmente no ensino fundamental, o envolvimento emocional vivido por elas é muito mais intenso. Além disso, as questões culturais e a divisão desigual de tarefas entre os gêneros contribuem para que, com frequência, se atribua o papel de cuidador às mulheres. As professoras podem se sentir mais 
"responsáveis" por seus alunos. Mais uma atribuição que contribui para que ocorra um maior acúmulo de atividades e implicações emocionais, gerando maior carga de responsabilidade e estresse. O adoecimento crescente dos profissionais da educação compromete/prejudica a qualidade das aulas e da formação dos alunos; existe um círculo vicioso: carência de professores, falta de aulas e desmotivação dos alunos.

Acerca dos professores licenciados por saúde que retornam ao ambiente de trabalho, a grande maioria não apresenta o mesmo desempenho anterior ao adoecimento e geralmente acaba exercendo atividades com delimitações de função, sempre acompanhados por outros profissionais, tais servidores constam nos registros das CREs como servidores ativos mesmo exercendo atividades secundárias, o que prejudica a alocação de recursos humanos e muitas vezes gera entraves para a solicitação de profissionais.

Além dos casos de adoecimento, a falta de professores e funcionários é cotidiana, o que, mais uma vez, reverbera na qualidade do ensino visto que, mesmo com arranjos e permuta de professores, as escolas e a Coordenadoria de Educação não conseguem sanar o problema das lacunas de professores em tempo hábil, para que não haja prejuízo para as escolas, demais professores e alunos. Mesmo com a existência de um sistema de informações de recursos humanos a Coordenadoria geralmente não obtém êxito nesta tarefa. As escolas já iniciam o período letivo com menos profissionais do que o necessário. Logo, as equipes diretivas se veem obrigadas a fazer vários arranjos para sanar a falta de docentes. Nesse transcurso, ainda acontecem entraves e demora para a alocação de recursos humanos devido a existência de processos demasiadamente burocráticos e engessados que acabam resultando também morosos. Como sugestão, as professoras destacam que uma forma de amenizar o problema da carência de professores seria a institucionalização de um cargo de professor substituto, o que conforme o relato já foi uma prática de anos atrás.

Os relatos feitos pelas entrevistadas deste estudo demonstram, com clareza, a objetificação do trabalho do docente e a precarização, que é resultante de uma lógica em que se mercantiliza tanto estudo como educação. Mas demonstram também que existe valor na percepção do trabalho e uma busca por satisfação individual associada a profissão. 
O fato de existir valor para o trabalhador, associado a uma perspectiva de que a educação deveria ser tratada como basilar para o desenvolvimento humano e consequentemente para o desenvolvimento da sociedade poderia alterar o cenário de adoecimento e alienação do trabalho docente. Com o amadurecimento de uma ideia de trabalho que vá além de uma lógica de troca. Onde o cenário da centralidade do trabalho possa ser fundo para a evolução do debate sobre ele, como meio de desenvolvimento econômico e social e não meramente de crescimento econômico.

\section{Referências}

BRASIL. Lei de diretrizes e bases da educação nacional. (1996). Lei no 9.394, de 20 de dezembro de 1996. Estabelece as diretrizes e bases da educação nacional. Disponível em: <http://www.planalto.gov.br/ccivil_03/leis/l9394.htm>. Acesso em: 9 jun. 2017.

BRASIL. Ministério da Saúde. Organização Pan-Americana da Saúde no Brasil. Doenças Relacionadas ao Trabalho: manual de procedimentos para os serviços de saúde. Brasília, DF. 2001. Disponível em: <http://renastonline.ensp.fiocruz.br/sites/default/files/arquivos/recursos/doenca s_relacionadas_trabalho_manual.pdf>

Acesso em: 10 dez. $201 \overline{7}$.

CABRAL, A. P. T. et al. O estresse e as doenças Psicossomáticas. Revista de Psicofisiologia, Belo Horizonte; v. 1. n. 1 e 2. 1997.

DAVIDOFF, L. L. Introdução à Psicologia. 3. ed. São Paulo: Person Macron Books, 2001.

DENZING, N. K.; LINCON, Y. S. O Planejamento da Pesquisa Qualitativa: teorias e abordagens. Porto Alegre: Artmed, 2006.

FERREIRA, M. C.; MENDES, A. M. "Só de pensar em vir trabalhar, já fico de mau humor": atividade de atendimento ao público e prazer e sofrimento no trabalho. Estudos de Psicologia, Natal. v. 6, n. 1, p. 93-104, jun. 2001.

FLICK, U. Introdução à Pesquisa Qualitativa. 3. ed. Porto Alegre: Artmed, 2009, 2009.

GIL, A. C. Como elaborar projetos de pesquisa. 5. ed. São Paulo: Atlas, 2010.

HELLER, A. O Cotidiano e a História. Rio de Janeiro, RJ: Editora Paz e Terra, 2016. 
JACQUES, M. G. C. Saúde do Trabalhador: uma urgência, uma busca, uma ética, um espaço. Revista Democracia e Mundo do Trabalho, Porto Alegre. a.1. n. 1. Jan/jun. 2005.

KRAWULSKI, E. A orientação profissional e o significado do trabalho. Revista da ABOP, Porto Alegre, v. 2, n. 1, p. 5-19, 1998.

LARA, D. Temperamento Forte e Bipolaridade: dominando os altos e baixos do humor. 8. ed. Porto Alegre: Revolução de Ideias, 2004.

LIPOWISKI, Z. J. What does the word ' psychosomatic' really mean? A historical and semantic inquiry. Psychosomatic Medicine, v. 46, n. 2, p. 153-171. Mar/abr 1984.

LEVY, G. C. T. M. Avaliar o índice de Burnout em professores da rede pública de ensino localizada na região sudeste. 2006. 166 f. Dissertação (Mestrado em Educação) Faculdade de Educação - Universidade do Estado do Rio de Janeiro, Rio de Janeiro, 2006.

MARX, K. O capital. Trad. Reginaldo Sant'Anna. 30å ed. Rio de Janeiro: Civilização Brasileira, 2012. $1 \mathrm{v}$.

MARX, K; ENGELS, F. A ideologia alemã. Trad. Rubens Enderle. Nélio Schneider, Luciano Cavini Martorano. São Paulo: Boitempo, 2007.

MORIN, E. M.; AUBÉ, C. Psicologia e Gestão. São Paulo: Atlas, 2009.

MORO, A. B. et al. Fatores motivacionais e higiênicos considerados relevantes na visão dos docentes e discentes de programas de pós-graduação de uma instituição pública federal. SOCIAIS E HUMANAS Santa Maria. v. 26, n. 3, p. 608-621, set/dez 2013.

MUCHINSKY, P. M. Psychology Applied to Work: An Introduction to Industrial and Organizational Psychology. 8th ed. Belmont: Thompson Learning. 2006.

MAX-NEEF, M. A. Human Scale Development: conceptions, application and further reflections. New York, New York: The Apex Press, 2011.

NUNES, A. V. L.; LINS, S. L. B. Servidores públicos federais: uma análise do prazer e sofrimento no trabalho. Psicologia: Organização e Trabalho, Brasília v. 9, n. 1, p. 51-67, 2009.

OLIVEIRA, J. F.; MANÃS, A. V. Tecnologia, Trabalho e Desemprego: Um conflito social. São Paulo: Érica Ltda. 2004.

ONU. Aumento dos casos de Depressão. 2017. Disponível em: $<$ https://nacoesunidas.org/oms-registra-aumento-de-casos-de-depressao-em-todoo-mundo-no-brasil-sao-115-milhoes-de-pessoas/>. Acesso em: 11 dez. 2017.

OPAS; OMS. OPAS e OMS apoiam governos no objetivo de fortalecer e promover a saúde mental da população. Disponível em 
$<$ https://www.paho.org/bra/index.php?option=com_content\&view=article\&id=5263: opas-oms-apoia-governos-no-objetivo-de-fortalecer-e-promover-a-saude-mentalda-populacao\&ltemid=839>. Acesso em: 18 dez. 2017.

PATTON, M. Qualitative research and evaluation methods: integrating Theory and Practice. $5^{\text {th }}$ ed. London: Sage Publications, 2002.

ÉPOCA NEGÓCIOS (Revista). Mais de 75 mil pessoas foram afastadas do trabalho por depressão em 2016. Disponível em $<$ https://epocanegocios.globo.com/Carreira/noticia/2017/02/mais-de-75-milpessoas-foram-afastadas-do-trabalho-por-depressao-em-2016.html>. Acesso em: 14 dez. 2017.

ROBBINS, S. P. Fundamentos do Comportamento Organizacional. 8 ed. São Paulo: Pearson Prentice Hall. 2009.

SILVA, L. C.; SALLES, T. L. A. F. O estresse ocupacional e as formas alternativas de tratamento. Revista de Carreiras e Pessoas (ReCaPe), São Paulo, v. 6, n. 2, p. 234-247, mai/jun/jul/ago. 2016.

SPURK, J. A noção de trabalho em Karl Marx. In: MERCURE, D. e SPURK, J. O Trabalho na História do Pensamento Ocidental. Petrópolis, RJ: Vozes, 2005.

VARELLA, D. Doenças e Sintomas. [S.I]. Disponível em <https://drauziovarella.uol.com.br/doencas-e-sintomas>. Acesso em: 10 dez. 2017.

YIN, R. K. Estudo de Caso: planejamento e métodos. 4 ed. Porto Alegre: Bookman. 2010.

ZANELLI, J. C. et al. Psicologia, Organizações e Trabalho no Brasil. Porto Alegre: Artmed. 2004. 